\title{
Relation between Sliding-Part Temperature and Clearance Shape of A Slipper in Swashplate Axial Piston Motors*
}

\author{
Toshiharu KAZAMA**, Motoshi SUZUKI***, Kenta SUZUKI****
}

\begin{abstract}
Temperature and behavior of a piston motor slipper were examined using a test rig. The experimental setup comprised a tester, a hydraulic circuit, control units, and measuring instruments. The tester included a servomotor and a chamber enclosing two piston assemblies with slippers, a rotating disk, displacement sensors, and thermocouples. The sliding surface diameter of the test slipper was $32 \mathrm{~mm}$; the test oil was hydraulic oil with VG46. Tests were conducted at supply pressures up to $35 \mathrm{MPa}$, rotational speeds up to $26.7 \mathrm{~s}^{-1}$, and oil temperature of $30-50^{\circ} \mathrm{C}$. The pad temperature increased with the supply pressure and rotational speed. The pad established a temperature gradient, being maximized near the slightly-outer trailing edge and minimized near the leading edge. The temperature differences were influenced by the rotational speed, but were almost independent of the supply pressure.
\end{abstract}

Keywords: Tribology, Hydraulics, Bearing, Motor, Pump, Friction, Sensor, Experimental Analysis

\section{Introduction}

Hydraulic motors and pumps must transform energy with high power density and efficiency ${ }^{1)-2}$. As the discharge pressure and shaft speed increase, the bearing and sealing parts generate more heat. Moreover, as the component size becomes smaller, less heat is transferred to the outside and the cooling effect reduces. These phenomena cause performance degradation, wear, and seizure of the equipment, as well as property changes and reduce the life of the hydraulic oils.

Hydraulic motors and pumps are categorized into four types: swashplate axial piston, bent-axis piston, vane, and gear. The construction of swashplate axial piston motors and pumps is based on hydrostatic balance and a variable displacement mechanism. This category is consequently characterized by several advantageous properties, including high efficiency, high power density, and high response.

Swashplate axial piston motors and pumps are thus widely utilized in equipment, such as construction machinery, aircrafts, and machine tools. The prime bearing and sealing parts of the motors and pumps are the parts between the

\footnotetext{
Manuscript received November 27, 2014

** Muroran Institute of Technology (27-1, Mizumoto-cho, Muroran, Hokkaido, Japan)

E-mail: kazama@mmm.muroran-it.ac.jp

*** Hitachi Construction Machinery Co., Ltd. (650, Kandatsu-machi, Tsuchiura, Ibaraki, Japan)

**** Hitachi Ltd.

(832-2,Horiguchi, Hitachinaka, Ibaraki, Japan)
}

slipper and the swashplate, between the piston and the cylinder bore, and between the cylinder-block and the valveplate.

The slipper is one of the main elements because it supports the ends of the pistons under highly fluctuating load and sliding speed. The behaviors and motions of slippers have been established in several pioneering studies. In the 1960s and 1970s, Shute and Turnbull ${ }^{3)}$ and Böinghoff ${ }^{4)}$ investigated slippers under conditions of fluid film lubrication and parallel film thickness. In the 1980s Hook et al. discussed the effects of concave and convex shape of slipper lands ${ }^{5)}$ and the size of restrictors ${ }^{6}$. Iboshi and Yamaguchi considered the effects of eccentric load and pad inclination ${ }^{7)}$, conducted numerical calculations under mixed lubrication condition ${ }^{8)}$, performed test pump experiments ${ }^{9)}$, and proposed an optimum design based on minimum power loss ${ }^{10)}$. Other important studies have been conducted by Matsumoto and Ikeya ${ }^{11)}$, Yabe and Kubo ${ }^{12)}$, Harris et al. ${ }^{13)}$, Manring et al. ${ }^{14)}$, Kumar et al. ${ }^{15)}$, Bergada et al. ${ }^{16)}$, and Shenk and Ivantysynova ${ }^{17)}$.

Kazama and Yamaguchi investigated circular hydrostatic thrust pad bearings theoretically ${ }^{18)}$ and experimentally ${ }^{19)}$. Kazama et al. studied the effects of elastic deformation ${ }^{20)}$ on the hydrostatic bearings. They further extended the bearing model to the slipper model to examine the motion and the tribological characteristics ${ }^{21)-22}$, but have yet to completely clarify how the slipper motion ${ }^{23)-24)}$ is related to thermal behavior ${ }^{25)}$. The temperature variations are connected to the slipper behavior as well as to motor and pump performance. 
In this study, the temperature of the slipper land and the position of the slipper pad are simultaneously examined. The effects of operating conditions on the temperature rise and the relation between the temperature distributions and the clearance shape are discussed.

\section{Nomenclature}

$\begin{array}{lll}h & : & \text { Clearance } \\ h_{c} & : & \text { Center clearance } \\ N & : & \text { Disk rotational speed } \\ p_{s} & : & \text { Supply pressure } \\ R_{2} & : & \text { Outer radius of slipper land } \\ t & : & \text { Temperature } \\ t_{c} & : & \text { Oil temperature in chamber } \\ \alpha & : & \text { Slipper inclination angle } \\ \Delta t & : & \text { Pad temperature rise } \\ \Delta t_{m} & : & \text { Pad mean temperature rise } \\ \delta t & : & \text { Difference in temperature } \\ \theta & : & \text { Circumferential coordinate } \\ \phi & : & \text { Slipper azimuth angle } \\ \text { Subscript } & & \\ \text { max } & : & \text { Maximum } \\ \min & : & \text { Minimum }\end{array}$

\section{Experiment}

The experimental setup consisted of a tester, measuring instruments, control units, and a hydraulic circuit ${ }^{26)}$. The tester (see Fig. 1) primarily included an oil-bath type chamber and an electric servomotor (rated output $=4.4 \mathrm{~kW}$, rated torque $=28.4 \mathrm{~N} \cdot \mathrm{m}$, maximum rotational speed $=50 \mathrm{~s}^{-1}$ ).

The chamber enclosed two piston assemblies with slippers, displacement sensors (range $0-0.5 \mathrm{~mm}$, resolution $=0.1 \mu \mathrm{m}$ ), thermocouples (type $\mathrm{K}$, tolerance $\pm 2.5^{\circ} \mathrm{C}$ (class 2 in JIS, Japan Industrial Standards), $\phi 0.25)$, heaters $(2 \mathrm{~kW} \times 2)$, and a rotating disk (diameter $=272 \mathrm{~mm}$ ). One of the slippers was used for testing, the other for counter-balancing. The hydrostatic balance ratio, defined as the ratio of the load to the maximum hydrostatic load-carrying capacity ${ }^{18)}$ (equivalent to over-clamp ratio ${ }^{6}$ ), was 1.02 .

The main measuring instruments were as follows: 6 contacting type displacement sensors, 4 thermocouples, a pressure sensor $($ rating $=50 \mathrm{MPa}$, nonlinearity $=0.3 \% \mathrm{RO}$ ), and a data logger (internal effective resolution of 14 bits, sampling time $0.01-60 \mathrm{~s}$ ) with an A/D converter (16 bit, sampling frequency $=250 \mathrm{kHz}$ ). These instrumental systems allowed simultaneous measurement of the clearance shapes between the slipper and disk and the temperature distributions in the slipper pad ${ }^{26)}$.

Figure $2 \mathrm{a}$ is the top-view schematic of the slippers and disk and Figure $2 b$ is the photograph of the test slipper and the thermo-couples and the displacement sensors installed in the chamber. The effective diameter of the test slipper and the revolution diameter around the disk center were $32 \mathrm{~mm}$ and $110 \mathrm{~mm}$, respectively. An annular ring was mounted at the slipper pad because the pad was too small to fix the displacement sensors.

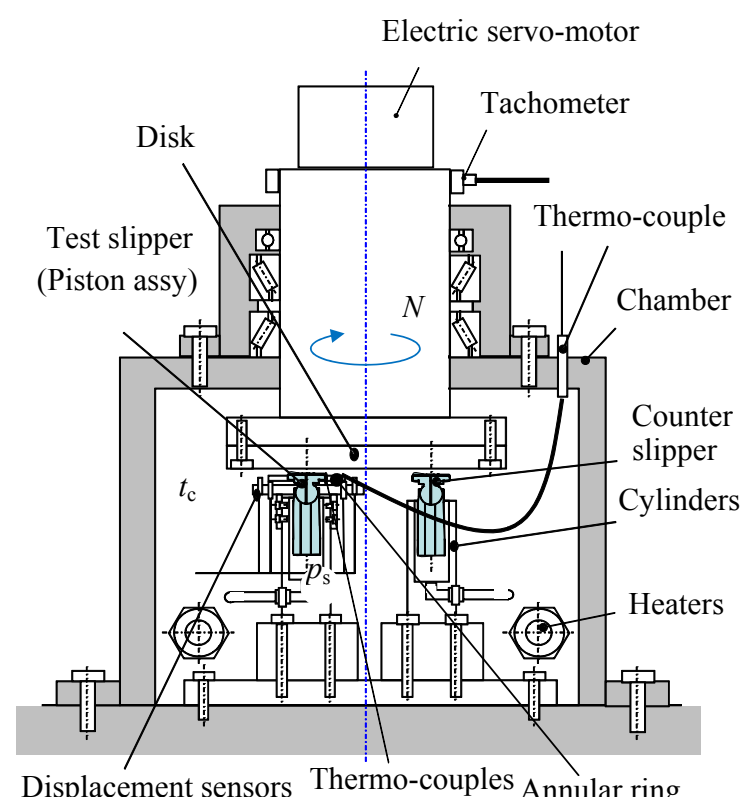

Fig.1 Illustration of the tester.

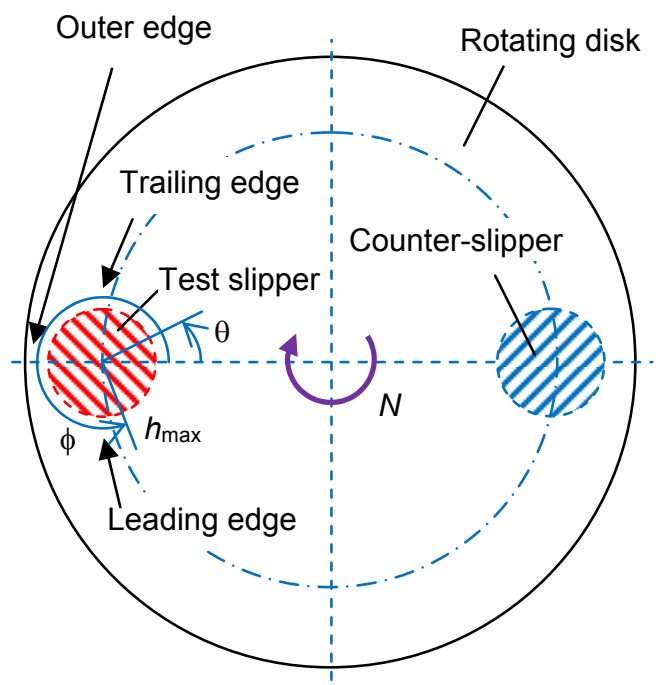

Fig.2a Schematic of the slippers and disk (Top-view). 


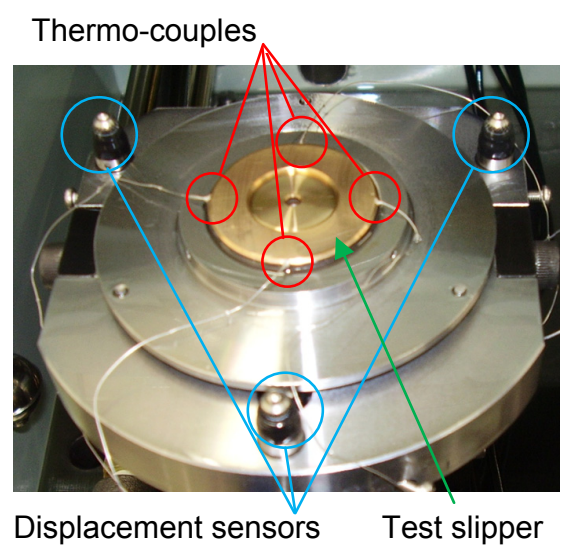

Fig.2b Photograph of the slipper and sensors (installed).

For measuring the disk fluctuation and distortion, the tips of three displacement sensors were contacted to the disk's surface. The absolute slipper displacement was measured by contacting the tips of the remaining three displacement sensors to the annular ring, which were placed behind the ring in Fig. 2b. Each pair of sensors was circumferentially positioned at $120^{\circ}$ intervals. The pitch diameter of the sensors' location on the annular ring was $76 \mathrm{~mm}$. The clearance between the slipper and disk was obtained from the differences in the outputs of the paired displacement sensors.

The four thermocouples were inserted at the side wall of the slipper pad. These were circumferentially positioned at $90^{\circ}$ intervals for measuring the temperature distributions across the pad. All displacement sensors and thermocouples were placed in the chamber, where they were exposed to oil.

The pressure sensor was positioned in the conduit between the discharge port of the power unit and the inlet port of the test rig. The temperature of the oil in the chamber was measured by another thermocouple placed close to the rotating disk. The rotational speed was measured by a tachometer fitted between the electric servomotor and disk. The tachometer also maintained a constant speed through feedback systems.

The hydraulic circuit comprised a hydraulic pump, a filter, valves, and a reservoir. The pump had a maximum discharge pressure of $72 \mathrm{MPa}$ and a discharge flow rate of $8.3 \times 10^{-6}$ $\mathrm{m}^{3} / \mathrm{s}$, while the filter had a maximum working pressure of 35 MPa and a mesh size of $8 \mu \mathrm{m}$.

The experiment was conducted as follows: the test chamber was filled with the test oil, and the remaining air was carefully removed. The oil temperature in the chamber was heated to the test condition by the heaters. The slipper and disk were closely contacted by a preload (supply pressure $=1 \mathrm{MPa}$ ) applied to the test slipper, and adjusted to zero. The disk was then rotated under the test condition. Furthermore, the supply pressure was increased from $5 \mathrm{MPa}$ to $35 \mathrm{MPa}$ in $5 \mathrm{MPa}$ increments and decreased from the maximum pressure to atmospheric pressure in $5 \mathrm{MPa}$ decrements.

The rotational speed was retained at the set condition by feedback with the servomotor. The operation was performed twice, and the second round data were repeatable and stable; hence, they were used in the analysis. The period between the previously set condition and the present condition was 5 $\mathrm{s}(1 \mathrm{MPa} / \mathrm{s})$. At each stage, the condition was held for $20 \mathrm{~s}$; the displacement, temperature, pressure, flow-rate, and torque were recorded by the $\mathrm{PC}$ and the logger.

In the experiment, the supply pressure $p_{s}$ was varied as 1 , $5,10,15,20,25,30$, and $35 \mathrm{MPa}$ ( 8 conditions); the rotational speed $N$ was varied as $3.3,6.7,10.0,13.3,16.7$, 20.0, 23.3, and $26.7 \mathrm{~s}^{-1}$ (8 conditions); and the oil temperature tc was varied as 30,40 , and $50^{\circ} \mathrm{C}$ ( 3 conditions). The test oil was hydraulic oil with ISO VG (viscosity grade) 46 (density $=862 \mathrm{~kg} / \mathrm{m}^{3}$ at $\left.15^{\circ} \mathrm{C}\right)$. The kinematic viscosity of the oil was 48.85 and $7.674 \mathrm{~mm}^{2} / \mathrm{s}$ at 40 and $100^{\circ} \mathrm{C}$, respectively; thus, at 30 and $50^{\circ} \mathrm{C}$, the kinematic viscosity was 78.4 and $32.5 \mathrm{~mm}^{2} / \mathrm{s}$, respectively.

\section{Results and discussion}

\subsection{Clearance and temperature distributions}

Figures 3 and 4 plot the circumferential distributions of the estimated clearance $h$ and the temperature difference $\Delta t$, respectively. The experimental conditions were $p_{s}=1,5-35$ $\mathrm{MPa}$ in $5 \mathrm{MPa}$ increments, the rotational speed of the disk $N$ $=26.7 \mathrm{~s}^{-1}$ (sliding speed at the slipper center $=9.2 \mathrm{~m} / \mathrm{s}$ ), and the oil temperature in the chamber $t_{c}=30^{\circ} \mathrm{C}$ (corresponding to a kinematic viscosity of $66.7 \mathrm{~mm}^{2} / \mathrm{s}$ ).

The clearance $h$ at the outer circumference of the rigid and flat slipper pad is given by

$$
h=h_{c}+\alpha R_{2} \cos (\theta-\phi)
$$

where $\alpha$ and $\phi$ denote the inclination and azimuth angles of the slipper, respectively, calculated from the normal vector obtained by the measured data of the displacement sensors; $h_{c}$ is the center clearance, given by the average of the three displacements; $\theta$ is the coordinate in the cylindrical system; 
and $R_{2}$ is the outer radius of the sliding surface of the pad. The coordinates and definition of inclination angle and azimuth of pad are described in Ref. 26.

The temperature rise is evaluated by the difference in temperature $\Delta t$ defined by

$$
\Delta t=t-t_{c}
$$

where $t_{c}$ is the oil temperature in the chamber and $t$ is the temperature of the slipper pad. In Fig. 4 the symbols are the measured data and the curves are fitted to a sinusoidal temperature distribution hypothesis given by

$$
t=a_{t}+b_{t} \cos \left(\theta-c_{t}\right)
$$

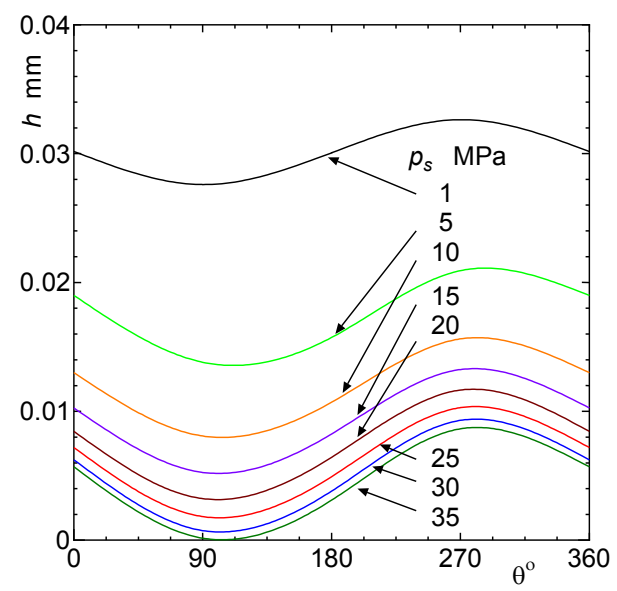

Fig. 3 Clearance distributions $h$ under different supply $p_{s}$ pressures $p_{s}\left(N=26.7 \mathrm{~s}^{-1}, t_{c}=30^{\circ} \mathrm{C}\right)$.

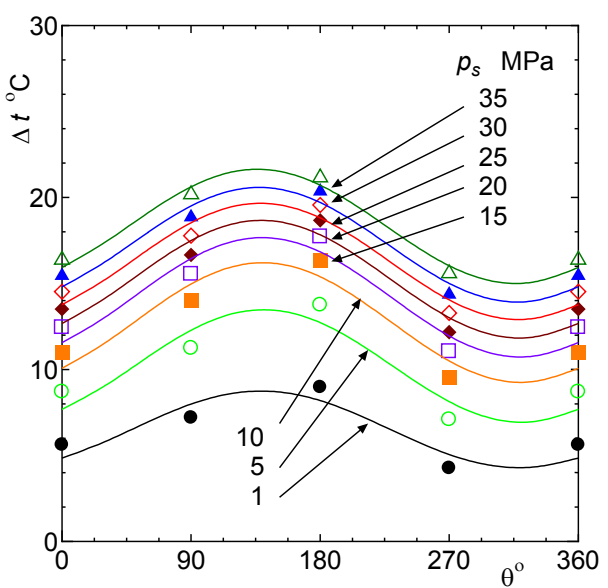

Fig.4 Distributions of temperature difference $\Delta t$ at different supply pressures $p_{s}\left(N=26.7 \mathrm{~s}^{-1}, t_{c}=30^{\circ} \mathrm{C}\right)$. where $a_{t}, b_{t}$, and $c_{t}$ denote the mean temperature, half the difference between the maximum and minimum temperature, and the circumferential angle at the maximum temperature, respectively.

The slipper was inclined, and the temperature of the pad was circumferentially distributed as shown in Fig. 4. As $p_{s}$ increased, the clearance $h$ decreased and the overall temperature increased. Under these conditions, the minimum clearance appeared at $\theta\left(h_{\min }\right)=90-105^{\circ}\left(\phi=270-285^{\circ}\right)$, while the maximum temperature obtained from the fitted curves was approximately at $\theta\left(t_{\max }\right)=120^{\circ}$.

Figure 5 compares the circular positions at minimum clearance $\theta\left(h_{\min }\right)$ and maximum temperature $\theta\left(t_{\max }\right)$ for various rotational speeds $\left(N=3.3,13.4\right.$, and $26.7 \mathrm{~s}^{-1}$, with $t_{c}$ $\left.=30^{\circ} \mathrm{C}\right)$. The angles $\theta\left(t_{\max }\right)$ and $\theta\left(h_{\min }\right)$ differ by around 30 $50^{\circ}$, except at $p_{s}=14-21 \mathrm{MPa}$ and below. It should be noted that the pad attitude $\phi$ was instable at lower $p_{s}$ because the load of pushing the pad onto the disk was small.

In other words, the minimum clearance appeared at the trailing edge and the temperature was also maximized near the trailing edge side. In contrast, the clearance was maximized and the temperature was minimized close to the leading edge side. The temperature may have been circumferentially maximized slightly near outer side of the disk beyond the trailing edge because the viscous friction generated by the rapid sliding speed might be significantly larger than the solid friction induced by partial contact. That is, the system operated in fluid film lubrication rather than mixed and boundary lubrication.

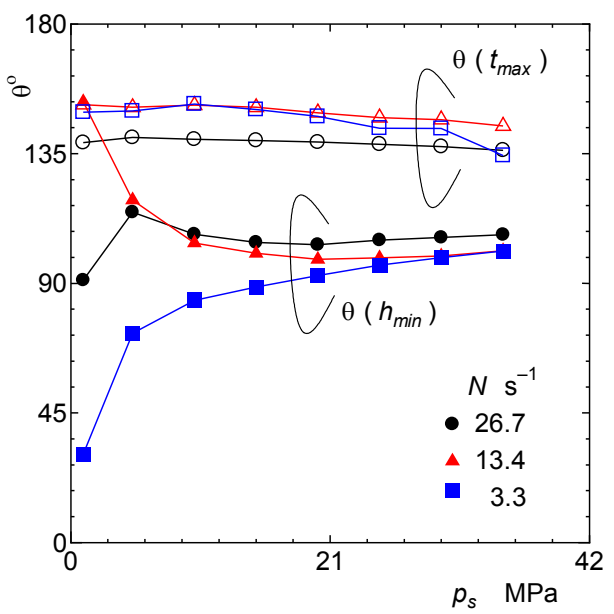

Fig. 5 Comparison of the circular position at minimum clearance $\theta\left(h_{\min }\right)$ and maximum temperature $\theta\left(t_{\max }\right)$ $\left(t_{c}=30^{\circ} \mathrm{C}\right)$. 


\subsection{Effects of operating conditions on clearance shape}

Figures 6-8 show contour plots of $h_{c}$, $\alpha$, and $\phi$ of the slipper pad, respectively. In all plots, the oil temperature $t_{c}$ is $30^{\circ} \mathrm{C}$.

The $h_{c}$ was estimated by averaging the measured data at three positions. The angle $\alpha$ and azimuth $\phi$ were also calculated from the clearance sensors' $\operatorname{data}^{26)}$. As the $p_{s}$ increased and the rotating speed $N$ decreased, the clearance $h_{c}$ decreased. Similarly, the clearance of a sliding bearing was determined by the wedge effect of the hydrodynamic lubrication. In contrast, the angles $\alpha$ and $\phi$ showed little variation. At speeds $N$ around $10-13.3 \mathrm{~s}^{-1}$ and $20 \mathrm{~s}^{-1}, h_{c}, \alpha$, and $\phi$ were all rather singular, perhaps, because the rotational speed $N$ almost coincided with the natural resonance frequency of the tester.

\subsection{Effects of operating conditions on temperature rise}

Figures 9-11 plot the maximum temperature differences $\Delta t_{\max }$ of the slipper land at oil temperature $t_{c}=30,40$, and $50^{\circ} \mathrm{C}$, respectively. The temperature difference $\Delta t_{\max }$ at the top right corner in Fig. 9 exceeded $20^{\circ} \mathrm{C}$, and $\Delta t_{\max }$ at the bottom left corner in Figs. 10 and 11 was under zero. The contours of the temperature $\Delta t_{\max }$ undulated around $N=$ $10-13.3 \mathrm{~s}^{-1}$ and $N=20 \mathrm{~s}^{-1}$. As discussed for Figs. 6-8, this phenomenon might be attributable to resonance, which yielded instability of the pad attitude and variability of the minimum clearance location. With increasing $p_{s}$ and rotational speed $N$, the temperature $\Delta t_{\max }$ increased at all oil temperatures $t_{c}$.

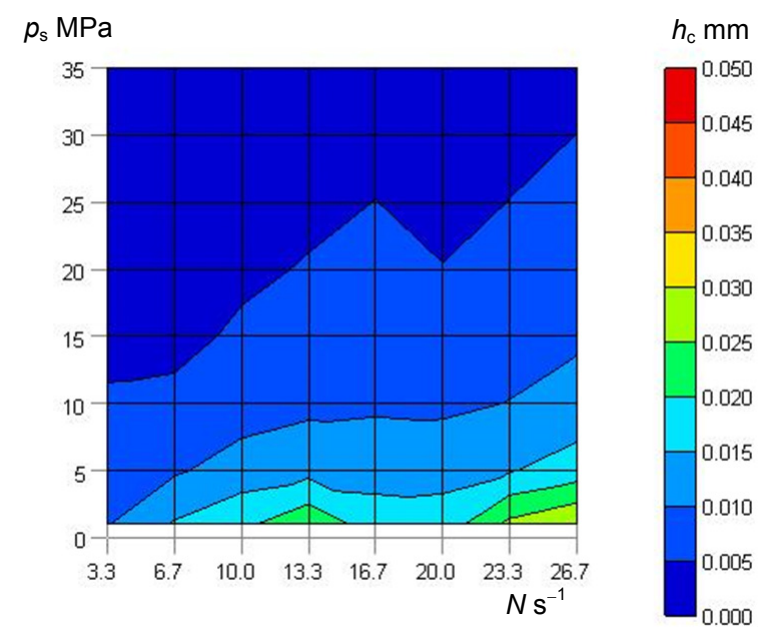

Fig.6 Contour plots of center clearance $h_{c}$, varying the supply pressure $p_{s}$ and rotational speed $N\left(t_{c}=30^{\circ} \mathrm{C}\right)$.

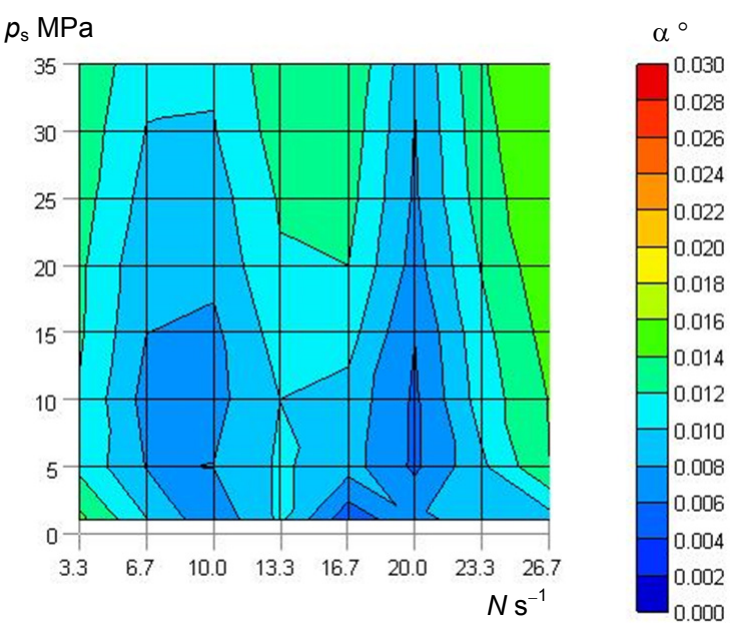

Fig.7 Contour plots of inclination angle $\alpha$, varying supply pressure $p_{s}$, and rotational speed $N\left(t_{c}=30^{\circ} \mathrm{C}\right)$.

$p_{\mathrm{s}} \mathrm{MPa}$

$\phi^{\circ}$

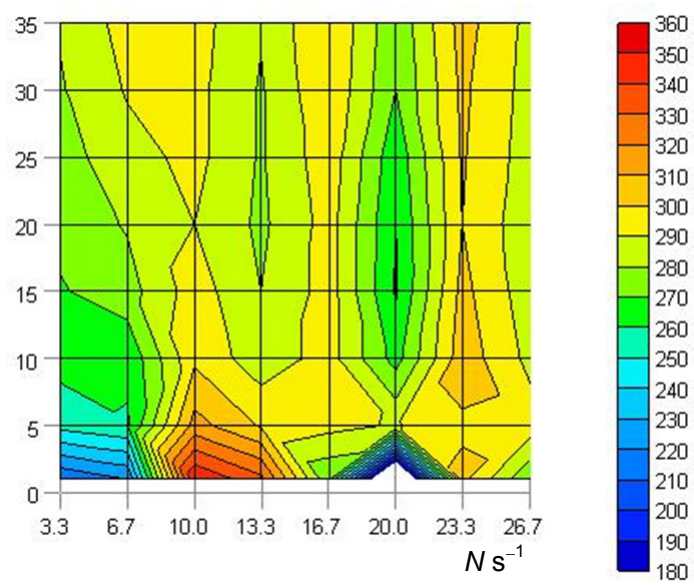

Fig.8 Contour plots of pad azimuth $\phi$, varying the supply pressure $p_{s}$ and rotational speed $N\left(t_{c}=30^{\circ} \mathrm{C}\right)$.

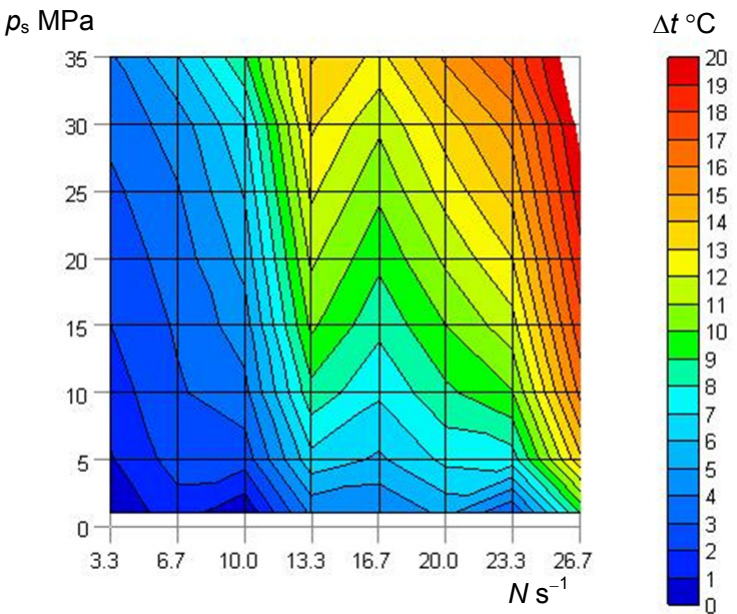

Fig.9 Contour plots of maximum temperature $\Delta t_{\max }$, varying the supply pressure $p_{s}$ and rotational speed $N\left(t_{c}=30^{\circ} \mathrm{C}\right)$. 
A representative example of the minimum temperature $\Delta t_{\text {min }}$ distribution at $t_{c}=30^{\circ} \mathrm{C}$ is given in Fig. 12. As a function of $p_{s}$ and $N$, the minimum temperature $\Delta t_{\text {min }}$ followed similar trends to the maximum temperature $\Delta t_{\max }$.

The rise in temperature of the slipper causes thermal deformation and the difference in pad temperature may cause thermal distortion. Therefore, these features are worthy of further investigation. Figures 13-15 display the contours of the differences $\delta t$ between the maximum and minimum temperatures of the slipper land, defined by $\delta t=\Delta t_{\max }-\Delta t_{\min }$ $\left(=t_{\max }-t_{\min }\right)$.

The temperature differences $\delta t$ depended on the rotational speed $N$, but were independent of $p_{s}$ at all oil temperature $t_{c}$. Since the sliding parts were mainly operated in fluid film lubrication, it is supposed that heat generation was almost

$p_{\mathrm{s}} \mathrm{MPa}$

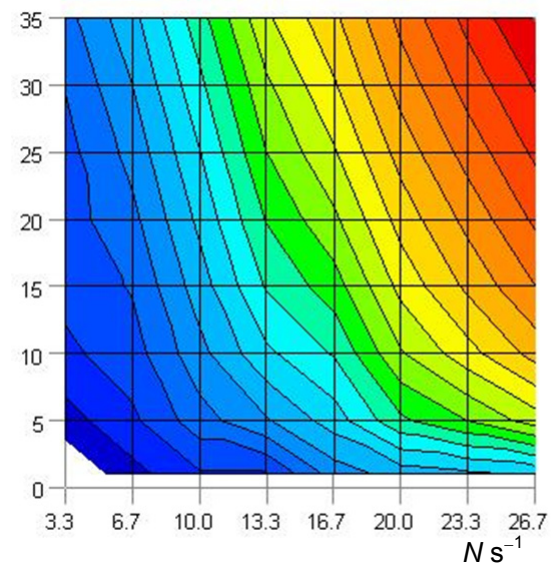

$\Delta t^{\circ} \mathrm{C}$

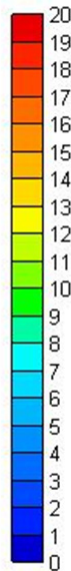

Fig.10 Contour plots of maximum temperature $\Delta t_{\max }$, varying the supply pressure $p_{s}$ and rotational speed $N\left(t_{c}=40^{\circ} \mathrm{C}\right)$.

\section{$p_{\mathrm{s}} \mathrm{MPa}$}

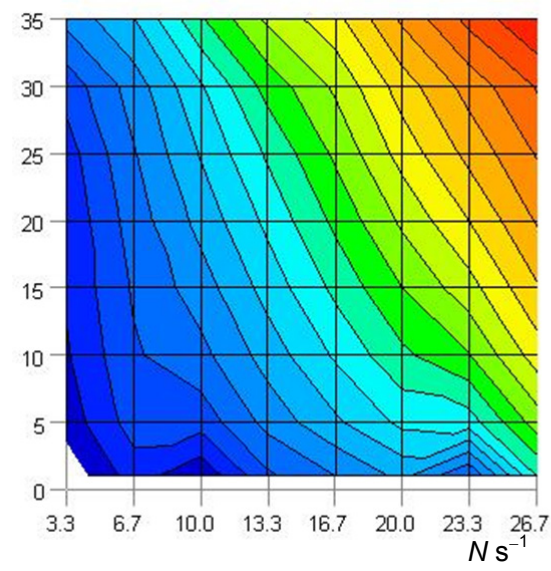

$p_{\mathrm{s}} \mathrm{MPa}$

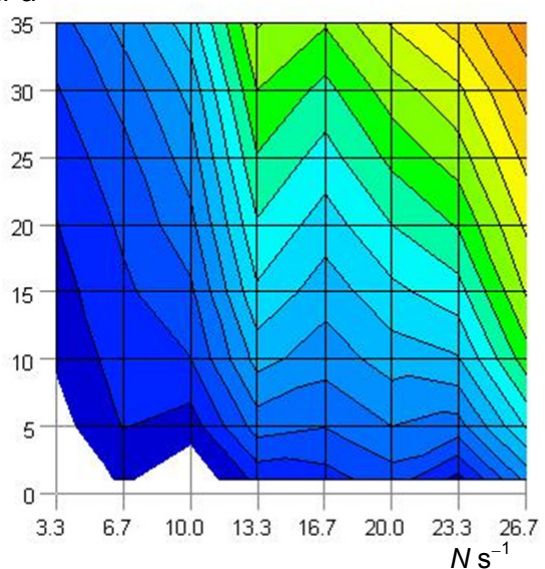

$\Delta t^{\circ} \mathrm{C}$

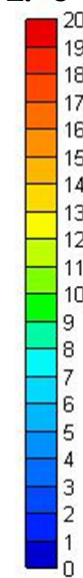

Fig. 12 Contour plots of minimum temperature $\Delta t_{\min }$, varying the supply pressure $p_{s}$ and rotational speed $N\left(t_{c}=30^{\circ} \mathrm{C}\right)$.

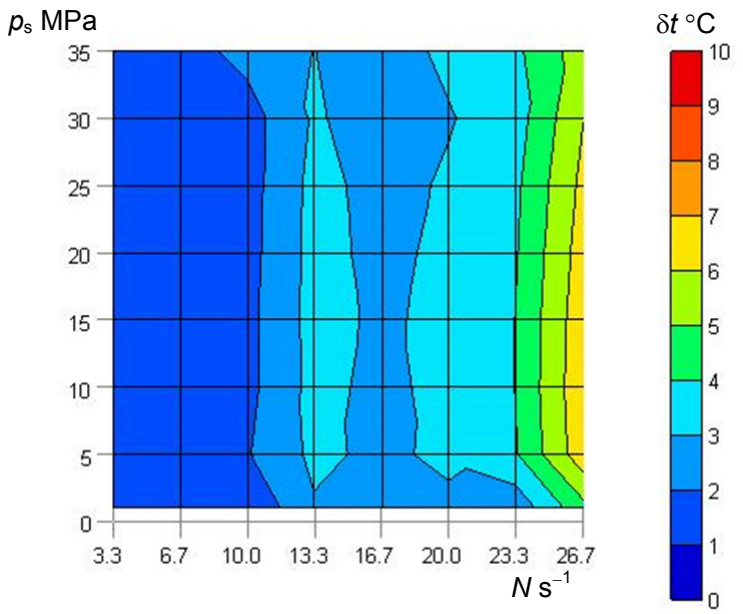

Fig. 13 Contour plots of differences in temperature $\delta t$, varying the supply pressure $p_{s}$ and rotational speed $N\left(t_{c}=30^{\circ} \mathrm{C}\right)$.

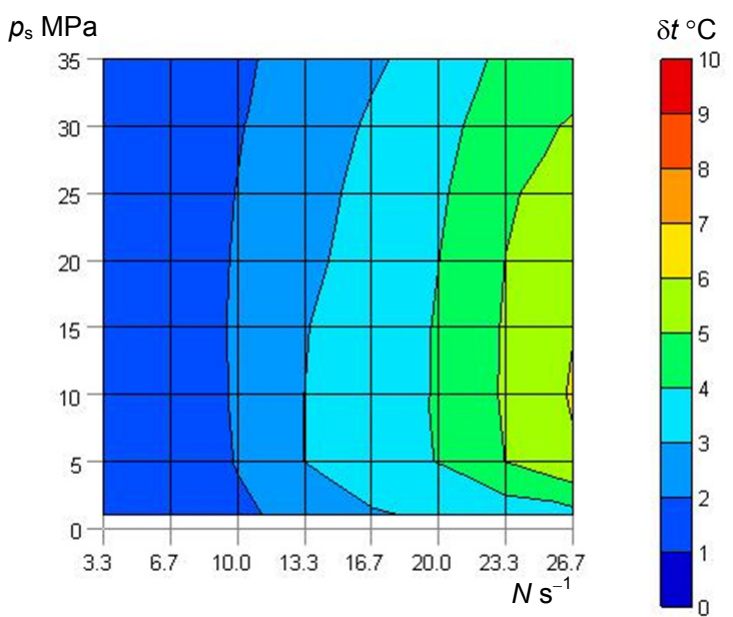

Fig. 14 Contour plots of differences in temperature $\delta t$, varying the supply pressure $p_{s}$ and rotational speed $N\left(t_{c}=40^{\circ} \mathrm{C}\right)$. 


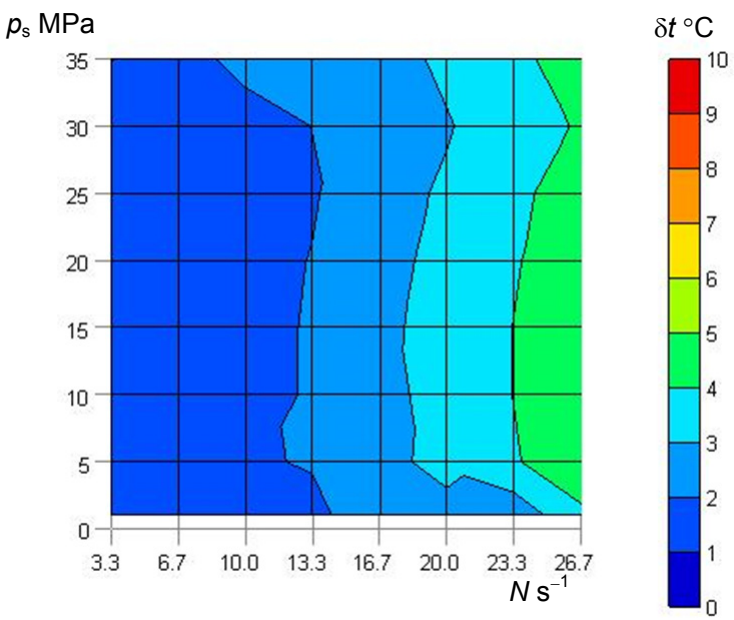

Fig. 15 Contour plots of differences in temperature $\delta t$, varying the supply pressure $p_{s}$ and rotational speed $N\left(t_{c}=50^{\circ} \mathrm{C}\right)$.

dominated by the dissipation term of the energy equation, and that solid friction generated by metallic contact at most exerted a negligible effect. Comparing Figs. 13-15, both $\delta t$ and $\Delta t_{\max }$ were observed to be higher at lower oil temperature $\left(t_{c}=30^{\circ} \mathrm{C}\right)$ than at higher oil temperature $\left(t_{c}=\right.$ $\left.50^{\circ} \mathrm{C}\right)$.

\section{Conclusions}

The temperature and behavior of the slipper pad of swashplate type axial piston motors were measured under real operating conditions up to $35 \mathrm{MPa}$ and $26.7 \mathrm{~s}^{-1}$. The difference in the temperature distributions of the pad was about $5^{\circ} \mathrm{C}$ and the rise in the maximum temperature was over $20^{\circ} \mathrm{C}$ under the high pressure and speed conditions. The salient conclusions are summarized below:

(i) The temperature difference distributions of the slipper pad between the maximum and minimum depended on the rotational speed but were independent of supply pressure.

(ii) The temperature of the pad was highest near the trailing edge of the outer-leaning disk rim and lowest near the leading edge.

(iii) The pad temperature increased with increasing supply pressure and rotational speed.

(iv) As the oil temperature was lowered, the increase in temperature became more pronounced.

\section{Acknowledgements}

The authors would like to appreciate Mr. S. Sakurai and Dr. H. Akita of Hitachi Construction Machinery; Mr. M.
Hemmi of Hitachi Ltd.; and Mr. M. Ochiai of Kyoritsu Kiden Co. Ltd. They would also like to thank Dr. Y. Narita and Mr. Y. Niida of Muroran Institute of Technology and Mr. K. Shiraki, a former student of the institute.

\section{References}

1) Yamaguchi, A.: Lubrication in Oil-Hydraulic Equipment (in Japanese), Journal of Japan Society of Lubrication Engineers, Vol.31, No.10, p.685-690 (1986)

2) Totten, G. E. and De Negri, V. J.: Handbook of Hydraulic Fluid Technology, Second Edition, CRC Press (2011)

3) Shute, N. A. and Turnbull, D. E.: Minimum Power Loss of Hydrostatic Slipper Bearings for Axial Piston Machines, Proceedings of International Convention of Lubrication and Wear, p.3-14 (1963)

4) Böinghoff, O.: Untersuchungen zum Reibungsverhalten der Gleitschuhe in Schrägsch EibenAxialkolbenmaschinen, VDI-Forsch.-Heft, Vol.584, p.1-46 (1977)

5) Hooke, C. J.: The Effects of Non-flatness on the Performance of Slippers in Axial Piston Pumps, Journal of Engineering Tribology, Proceedings of Institution of Mechanical Engineers, Prt.C, Vol.197, p.239-247 (1983)

6) Koç, E. and Hooke, C. J.: Investigation into the Effects of Orifice Size, Offset and Overclamp Ratio on the Lubrication of Slipper Bearings, Tribology International, Vol.29, No.4, p.299-305 (1966)

7) Iboshi, M. and Yamaguchi, A.: Characteristics of a Slipper Bearing for Swash Plate Type Axial Piston Pumps and Motors: 1st Report, Theoretical Analysis, Bulletin of Japan Society of Mechanical Engineers, Vol.25, No.210, p.1921-1930 (1982)

8) Iboshi, M. and Yamaguchi, A.: Characteristics of a Slipper Bearing for Swash Plate Type Axial Piston Pumps and Motors: 2nd Report, Experiment, Bulletin of Japan Society of Mechanical Engineers, Vol.26, No.219, p.1583-1589 (1983)

9) Iboshi, M.: Characteristics of a Slipper Bearing for Swash Plate Type Axial Piston Pumps and Motors: 3rd Report, Design Method for a Slipper with a Minimum Power Loss in Fluid Lubrication, Bulletin of Japan Society of Mechanical Engineers, Vol.29, No.254, p.2529-2538 (1986) 
10) Iboshi, M. and Yamaguchi, A.: Characteristics of a Slipper Bearing for Swash Plate Type Axial Piston Pumps and Motors: 4th Report, Effects of Surface Rough, Bulletin of Japan Society of Mechanical Engineers, Vol.29, No.254, p.2539-2546 (1986)

11) Matsumoto, K. and Ikeya, M.: Friction and Leakage Characteristics between the Valve Plate and Cylinder for Starting and Low-Speed Conditions in a Swashplate-Type Axial Piston Motor (in Japanese), Transactions of Japan Society of Mechanical Engineers, Ser.C, Vol.57, No.541, p.3013-3018 (1991)

12) Yabe, H. and Kubo, A.: Fundamental Characteristics of Slipper Bearings in Swash Plate Type Axial Piston Pumps and Motors: 1st Report, Fundamental Bearing Characteristics (in Japanese), Transactions of Japan Society of Mechanical Engineers, Ser.C, Vol.63, No.608, p.1350-1356 (1997)

13) Harris, R. M., Edge, K. A., Tilley, D. G.: Predicting the Behavior of Slipper Pads in Swashplate-Type Axial Piston Pumps, Journal of Dynamic Systems, Measurement and Control, Transactions of American Society of Mechanical Engineers, Vol.118, No.1, p.4147 (1996)

14） Manring, N. D., Johnson, R. E., Cherukuri, H. P.: The Impact of Linear Deformations on Stationary Hydrostatic Thrust Bearings, Journal of Tribology, Transactions of American Society of Mechanical Engineers, Vol.124, No.4, p.874-877 (2002)

15) Kumar, S., Bergada, J. M., Watton J.: Axial Piston Pump Grooved Slipper Analysis by CFD Simulation of Three-Dimensional NVS Equation in Cylindrical Coordinates, Computers and Fluids, Vol.38, No.3, p.648-663 (2009)

16) Bergada, J. M., Watton, J., Haynes, J. M., Davies, D. L.: The Hydrostatic/Hydrodynamic Behaviour of an Axial Piston Pump Slipper with Multiple Lands, Meccanica, Vol.45, No.4, p.585-602 (2010)

17) Schenk, A. and Ivantysynova, M.: An Investigation of the Impact of Elastohydrodynamic Deformation on Power Loss in the Slipper Swashplate Interface, Proceedings of 8th JFPS International Symposium on Fluid Power, Okinawa, 1C2-5, p.228-234 (2011)

18) Kazama, T. and Yamaguchi, A.: Application of a Mixed Lubrication Model for Hydrostatic Thrust Bearings of Hydraulic Equipment, Journal of Tribology, Transactions of American Society of
Mechanical Engineers, Vol.115, No.4, p.686-691 (1993)

19) Kazama, T. and Yamaguchi, A.: Experiment on Mixed Lubrication of Hydrostatic Thrust Bearings for Hydraulic Equipment, Journal of Tribology, Transactions of American Society of Mechanical Engineers, Vol.117, No.3, p.399-402 (1995)

20) Kazama, T., Fujiwara, M., Yamaguchi, A.: High Pressure Hydrostatic Thrust Bearings in Mixed Lubrication-Effects of Elastic Deformation on Optimum Conditions, Proceedings of 17th International Congress of Mechanical Engineering, COBEM2003, 1915, CD-ROM (2003)

21) Kazama, T.: Numerical Simulation of A Slipper Model for Water Hydraulic Pumps/Motors in Mixed Lubrication, Proceedings of 6th Japan Fluid Power Society International Symposium on Fluid Power, Tsukuba, 2C4-5, CD-ROM (2005)

22) Kazama, T. and Narita, Y.: Numerical Simulation of a Slipper Model for Swash Plate Type Axial Piston Pumps and Motors: Effects of Concave and Convex Surface Geometry, International Journal of Automation Technology, Vol.6, No.4, p.434-439 (2012)

23) Saito, T., Kazama, T., Narita, Y., Suzuki, M., Akita, H.: Measurement of Frictional Torque and Clearance Shape of Slippers for Swashplate-Type Axial Piston Motors, Proceedings of Thailand-Japan International Symposium in Industrial Engineering, Mechanical Engineering and Robotics, JP01, p.1-4 (2010)

24) Suzuki, M., Akita, H., Saito, T., Kazama, T.: Experiment on Behavior of Slippers for SwashplateType Axial Piston Motors, Proceedings of 8th Japan Fluid Power Society International Symposium on Fluid Power, Okinawa, 1B3-1, p.157-162 (2011)

25) Kazama, T.: Thermohydrodynamic Lubrication Model Applicable to a Slipper of Swashplate Type Axial Piston Pumps and Motors (Effects of Operating Conditions), Tribology Online, Vol.5, No.5, p.250-254 (2010)

26) Kazama, T., Suzuki, M., Suzuki, K., Narita, Y., Sakurai, S.: Simultaneous Measurement of SlidingPart Temperature and Clearance Shape of A Slipper Used in Swashplate Type Axial Piston Motors (in Japanese), Transactions of the Japan Hydraulics and Pneumatics Society, Vol.45, No.2, p.22-28 (2014) 